\title{
Communicating Unnatural Disasters
}

Robin Lacassin $€$, Iain Stewart ${ }^{£}$, Sylvain Lavelle $\S$

$€$ Institut de Physique du Globe de Paris, Sorbonne Paris Cité University, CNRS, FR.

$£$ Sustainable Earth Institute, Plymouth University, UK

§ ICAM Paris-Sénart, Ecole des Hautes études en Sciences Sociales, FR.

In the course and aftermath of Harvey and Irma category 5 hurricanes, the phrase 'natural disaster' has circulated repeatedly among the mainstream media, as it routinely does after any catastrophe deeply affecting humans, whether it is due to a massive earthquake or tsunami, or to a dramatic meteorological event. Again and again, news articles invoked the usual narrative clichés of 'record-breaking', 'biblical', 'Mother Nature's wrath' whilst social media exchanges implored us to 'pray for', say, Houston, Barbuda, Saint Martin, or Florida Keys, then for Dominica or Puerto Rico as the next hurricane Maria approached. As the sense of calamity was compounded by destructive earthquakes hitting Mexico, public discourse divided between narratives of divine intervention or natural violence. And yet this persistent popular dualism neglects the common culprit in modern disasters: human culpability.

In truth, the notion that natural catastrophes are far from natural is at least two and a half centuries old, and rooted in the famous literary exchange between Rousseau and Voltaire in the aftermath of Lisbon earthquake and tsunami in 1755: 'Without departing from your subject of Lisbon, admit, for example, that nature did not construct twenty thousand houses of six to seven stories there, and that if the inhabitants of this great city had been more equally spread out and more lightly lodged, the damage would have been much less and perhaps of no account. How many unfortunate people have perished in this disaster because of one wanting to take his clothes, another his papers, another his money? [1]

Rousseau's argument that the catastrophe was a social construction presents arguably the first coherent conceptualization of the modern notion of 'vulnerability' that is widely used by scientists and engineers working on disaster risk reduction. Among the disaster risk community it is accepted that although hurricanes, earthquakes, tsunamis, wildfires, whether massive or even extreme, emerge from Nature - that is, from the physical processes governing the earth system - natural events are not 'disasters' per se. Instead, it's only when combined with high vulnerability that the hazards due to an extreme natural event eventually causes a disaster. And because vulnerability depends on human actions (or non-action), whether they are political, economic, cultural or personal, the concept of 'natural disaster' is a non sequitur; 'Human disaster' is the true one. And Human disaster may come in different sub-disasters: economic, industrial, political or even personal.

Which is why, forty years ago, social scientists resurrected Rousseau's argument to "Remove the concepts of naturalness from natural disasters" [2]. Yet such is its enduring appeal that the notion of natural disasters remains embedded in public consciousness and entrenched not only in political discourse, but in many countries also in legal statutes. In climate science, however, the anthropogenic contribution to global warming is encouraging many scientists to rekindle the debate. Writing recently in the Washington Post, for example, the MIT hurricane scientist Kerry Emanuel complained that "the 
phrase 'natural disaster' [is] a sham we hide behind to avoid our own culpability.", noting that "Climate change acts as a threat-multiplier to these policy-generated disasters, making them progressively worse than they would have been in a stable climate."

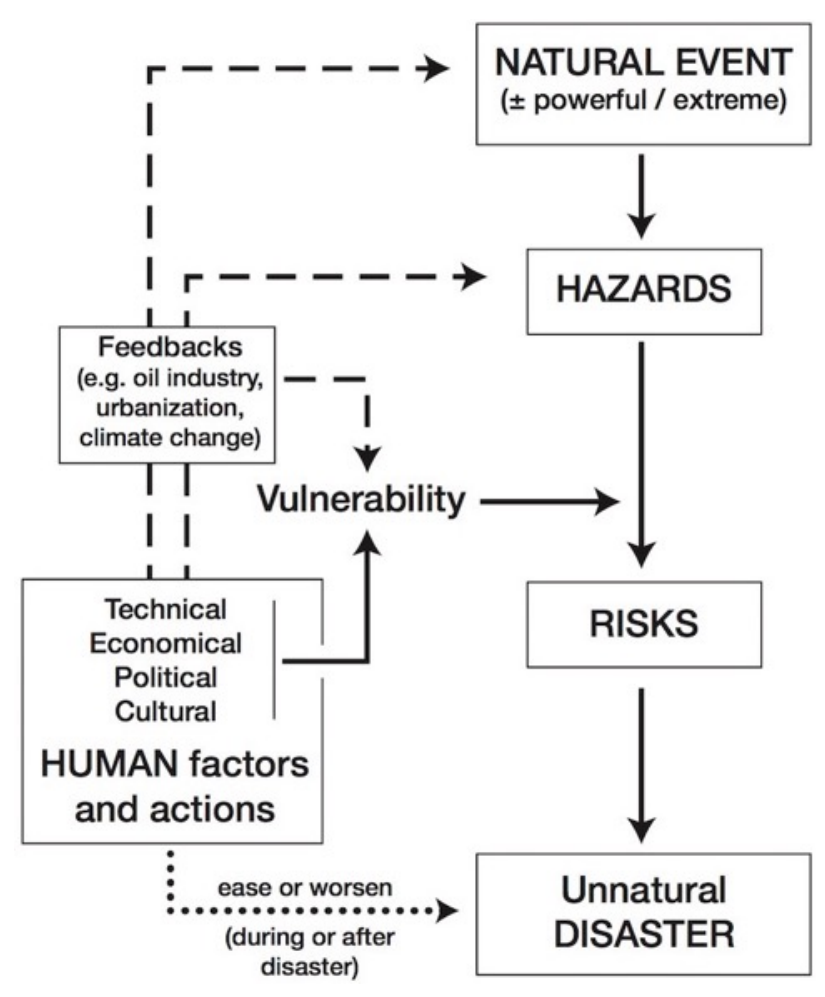

Figure 1: Vulnerability is at the core of the conventional chain from a natural event to the disaster. In the classical view, human factors and action impact the risk box only. Yet, growing imprint of humanity on earth physical processes suggests other feedbacks outlined here by dashed arrows.

But if human culpability fuels the growing 'unnaturalness' of hydro-meteo hazards, might a similar culpability extend also to the geophysical 'solid earth' realm? Although anthropogenic forcing readily impacts Earth's fluid envelopes, the operation of inner, deeper-seated dynamic processes would seem more obdurate and out of reach. Indeed, the vast majority of earthquakes or volcanic eruptions are the natural expression of tectonic forces. But many are not. The recent exponential rise of earthquakes in Central USA is undoubtably triggered by oil industry injecting massive amounts of wastewater a few kilometers deep [3]. Oklahoma's current seismic crisis delivers the message that humans are now able to modulate even the subsurface geophysical realm. These induced earthquakes were damaging rather than destructive but elsewhere induced seismicity can be lethal, as in 2011 in Lorca, Spain, where a magnitude 5.1 event was induced by groundwater pumping [4]. A human trigger has even been proposed for much larger magnitude events, such as the 1952 Kern County Mw 7.5 earthquake in California [5]. As society makes more and more large-scale interventions into the subsurface for resource extraction and storage, we are increasingly likely to perturb the local state of stress below ground. Above ground, unloading through erosion may modulate natural earthquake occurrence [6], and with climate change a strengthening driver for erosion we may hypothesize a longterm anthropogenic effect on earthquake rate. A similar unloading effect has been proposed for volcanism triggered by deglaciation due to climate change that will modify stresses in the lithosphere thus possibly raising eruption rates (7). 
Human modification to the deep geophysical realm may be nascent and still barely perceptible but it would seem that our 'classical' view of natural events as products of Earth's intrinsic physical processes is too simple and outdated. Humanity is now a climatic and geological agent, and feedbacks of social actions begin to exert influence not only on the planet's external vulnerability but also on its internal physics [8]. In this regard, we are modifying the links in the conventional disaster chain (see Figure): human action raises vulnerability, but also the severity of hazards, and in some case even the power or recurrence of the physical event itself. To help maintain the long-term wellbeing of human societies on this planet, it is now the responsibility of the Earth-science community to communicate not only the probable events inferred from the planet's past behaviour but also possible future scenarios in which geophysical hazards worsen because of our actions.

But what exactly is it that Earth scientists need to communicate? Conventionally the currency of academic discourse has been specialist knowledge and technical information, but recent years have seen a shift away from the one-way dissemination of scientific 'matters of fact' toward developing participatory dialogues around public 'matters of concern' $[9,10]$. As has been recognized in climate science, fusing technical know-how with people's concerns arising from their direct or indirect experience creates 'meaning', which is critical to truly understanding external threats [11]. In Oklahoma, it is residents' personal experience of the induced earthquake swarms that motivated some to issue legal action, which combined with expertise from USGS seismologists pressed state authorities to begin regulate wastewater injection. In Chile, in the absence of clear official warnings, many of those living on the coast escaped the 2010 tsunami because they understood the meaning of seismic shaking from previously experienced earthquakes.

In the context of disaster risk reduction, bridging the gap between knowledge and concerns to establish meaning requires Earth-scientists, social-scientists, engineers, and people from hazard-prone communities to converge $[12,13]$. To achieve this convergence, the knowledge exchange and communication efforts of scientists need a fresh framework for interpreting and intervening on geophysical events. At the level of philosophical interpretation, that framework can draw from recent advances in anthropological studies that question the human / non-human divide and account for the hybrid nature of phenomena at the crossroads of Nature and society [11, 14]. At the level of intervention, the new framework requires innovative organizational designs that promote knowledge brokering and an ongoing dialogue between knowledge producers and users $[15,16]$. This cooperative research - 'co-production' - makes it possible to provide contextual or contrarian inputs to establish a socially sensitive and robust knowledge base. Then, scientific information can be debated but also appropriated by other stakeholder groups, particularly at-risk communities, to create a common nexus of concern and meaning. With the frequency and intensity of 'unnatural disasters' likely to rise as anthropogenic influences strengthen, there is an urgent need for Earth science to connect the 'paradigm shift' in our representations of geophysical processes with the 'matrix shift' in societal and personal behaviour and habits. For disaster science, the ultimate challenge for this new way of planetary thinking will be how to translate collective knowledge into meaningful action on the ground.

[1] J.J. Rousseau (1756). The collective Press of New England, vol. 3, p 110 (1992)

[2] P. O’Keefe P., K. Wesgate K., B. Wisner, Nature, 260, 566-567 (1976)

[3] M. Weingarten, M., S. Ge, J.W. Godt, B.A. Bekins, J.L. Rubinstein, Science 348, 1336-1340 (2015) doi:

10.1126/science.aab1345 
[4] P.J. González, K.F. Tiampo, M. Palano, F. Cannavó, J. Fernández, Nature Geoscience, 5(11), 821 (2012) doi: 10.1038/NGEO1610

[5] S.E. Hough, V.C. Tsai, R. Walker et al., J. Seismol. (2017) https://doi.org/10.1007/s10950-017-9685-x

[6] P. Steer, M. Simoes, R. Cattin, J.B.H. Shyu, Nature communications, 5, 5564 (2014) doi:10.1038/ ncomms6564

[7] H. Tuffen, Phil. Trans. R. Soc., 368, 2535-2558 (2010) doi:10.1098/rsta.2010.0063

[8] N. Oreskes, Historical Social Research 40, 2, 246-270 (2015) doi:10.12759/hsr.40.2015.2.246-270

[9] National Academy of Sciences Engineering and Medicine, Communicating Science Effectively: A Research Agenda, The National Academies Press (2016)

[10] I.S Stewart \& D. Lewis, Earth Science Reviews, 174, 122-133 (2017) doi:10.1016/j.earscirev.2017.09.003

[11] S. Jasanoff, Theory Culture and Society, 27, 233-253 (2010) doi:10.1177/0263276409361497

[12] T. Davies and 16 others, Int J Disaster Risk Sci, (2015) doi: 10.1016/j.ijdrr.2015.05.009

[13] A. Aitsi-Selmi, V. Murray, C. Wannous, C. Dickinson, D. Johnston, A. Kawasaki, A-S. Stevance, T. Yeung, Int J Disaster Risk Sci, (2016) doi: 10.1007/s13753-016-0081-x

[14] B. Latour, We have never been modern, Harvard University Press (1993)

[15] M.K. McNutt, GeoHealth, 1, 2-3 (2017) doi:10.1002/2017GH000068

[16] J. G. Hering, Sustainablity Science, (2016) doi: 10.1007/s11625-015-0314-8

This short perspective paper has been rejected by Science after two rounds of exchanges with editors (resulting in substantial revisions) then 2 peer-reviews. The reviews were not enough positive, leading to rejection of the manuscript. Main critics were that the paper was presenting naïve views, setting up straw men, and that arguing that disasters should be called 'unnatural' is useless. With the aim to open the debate before reshaping the paper, we upload the preprint to EarthArXiv. Comments, discussions, suggestions, inputs are welcome! ( lacassin@ipgp.fr ) 